\title{
A Study of the Fire Aspect of Atria in Hong Kong
}

\author{
W. K. CHOW and W. K. WONG \\ Department of Building Services Engineering \\ Hong Kong Polytechnic \\ Hong Kong
}

\begin{abstract}
This paper reports on the fire safety aspect of atrium buildings in Hong Kong. The physical shape and geometrical configuration of the existing atria are surveyed. The general features of the layout of the local atria are then worked out. The fire regulation and the services designs are discussed. The fire environment that will be encountered in an atrium fire is studied by using the existing deterministic fire models, both zone and field. This includes the FIRST developed at the Fire Research Centre, NIST, and a self developed field model. The predicted results are applied to assess the installed fire services design such as high headroom sprinkler and smoke extraction systems.
\end{abstract}

\section{Keywords :}

fire environment, atrium fire, mathematical models, application of zone model and field model, fire services design, Hong Kong.

\section{(1) Introduction}

The atrium, although not a new concept with a two thousand year history, is very popular in Hong Kong. It can be found extensively in those buildings erected in or after the 80 s. Unlike the ancient ones, modern atria in Hong Kong are normally covered. The huge atrium space either communicates with the adjacent occupied space or is separated from other parts of the building by glazed areas. Among all the other technical problems in an atrium building, special attention must be paid to fire safety ${ }^{2,3}$. In contrast to high rise buildings and shopping complexes, it is difficult to predict atrium building fire scenarios. However people believe that during an atrium fire, smoke will give serious problems because it can spread easily throughout the atrium space and to other compartments at higher levels. Although there are not many examples of atrium fires ${ }^{4,5}$, past experience indicates that smoke could accumulate in the top of the atrium first and then log to the ground floor level to give serious problems. 
Since the fire problem in atrium buildings is different from the others, traditional concepts of fire safety would fail to apply. The design is very difficult because only some examples are available in the record for enabling the fire officers to set up new codes. Also performing fullscale burning tests is too expensive. But fortunately, building fire models, both field ${ }^{6-8}$ and zone $^{9-12}$, are available and can be applied to study the fire environment in an atrium.

In this paper, the geometrical shape of the atrium buildings is analyzed and reported in section (2). Their installed fire services system is also discussed. The capability of building fire models to simulate the atrium fire is demonstrated in section (3). Section (4) is discussion and section (5) records conclusions.

\section{(2) Atria in Hong Kong}

Over the past two decades, many atria of different size and shape were built in Hong Kong. Some of them are quite different from those in the others countries. For example, the largest one has a volume of more than $100,000 \mathrm{~m}^{3}$, the highest one has a height more than $60 \mathrm{~m}(15$ storeys) $)^{13}$ and the longest one has a length of $88 \mathrm{~m}$. Basically, the configuration of these atria can be grouped into three main categories :

(I) High - atrium with the height much larger than its width or length. The height is usually more than $40 \mathrm{~m}$ and this kind of atrium is commonly found in high rise office buildings and hotels. Typical examples of this type are the newly erected Bank of China Building and the Hong Kong Bank Building.

(II) Flat - atrium with a length or width much greater than its height. The size is usually very large and this kind of atrium is popular in multi-storey shopping malls. The longest one is the $88 \mathrm{~m}$ long atrium at the New Town Plaza.

(III) Cubic - this is the commonest type of atrium built in Hong Kong. It is constructed on a smaller scale and incorperated into the shopping area of multi-function commercial buildings.

Beside classifying according to the configuration, atria can also be further divided into types that are :

(1) open to the adjacent compartments;

(2) separated from the other parts of the buildings by glazing and;

(3) combination of the type (1) and (2).

For an open-side atrium (i.e. type 1), smoke can spread easily to the other part of the building. The area that will be affected by smoke will increase rapidly as the fire grows. Therefore, providing sufficient protection against smoke spread is very important. For an atrium which is separated from the other compartments by glazing (i.e. type 2), smoke can be confined more easily.

Since the large atrium floor area can be used for different purposes, it is difficult to estimate its combustible content. For example, the atrium floor can be used as an exhibition gallery in a shopping mall, a lobby floor in a hotel or a cafeteria in a shopping centre. Sometimes, it is even used as an ice skating rink. The fire load in the atrium floor will be varied from virtually zero in an ice skating rink to a very high value in a cafe.

Concerning regulation, there is no specific code ${ }^{16}$ and the fire services requirement for an atrium building depends on the classification of the building. But a smoke extraction system is required if the atrium volume is greater than $28,000 \mathrm{~m}^{3}$. The design of this smoke extraction system has to be approved by the Fire Services Department and will be examined individually. 
Since the volume of most of the atria in Hong Kong is smaller than this value, smoke extraction systems are not commonly installed. On the other hand, sprinkler systems are required for hotels, high rise office buildings and shopping complexes. Therefore, systems are installed in most of the atria because they are usually integrated into these kinds of premises. However, their effectiveness in controlling a fire is highly questionable and have been reported elsewhere ${ }^{17}$.

The Bank of China Building is one of the very few atrium buildings in Hong Kong that has been equipped with a smoke extraction system. It is the tallest in Hong Kong with a total volume of $33,050 \mathrm{~m}^{3}$ and height of more than $60 \mathrm{~m}$ (15 storeys). Since its volume is greater than $28,000 \mathrm{~m}^{3}$, the installation of a smoke extraction system capable of exhausting 8 air changes per hour was required. Two vaneaxial fans were installed in the equipment room at the high level of the atrium. Each fan has a flow capacity of $42,300 \mathrm{l} / \mathrm{s}$. Makeup air for the exhaust system is taken from the automatically operable panel in various locations. This system, including the electrical wiring, is rated at $250^{\circ} \mathrm{C}$ for one hour operation. The smoke extraction system will be started whenever any one of the smoke detectors, fire alarms or sprinkler water flow switches in areas that are opened to the atrium is activated. It has a manual control mode with the device in the building's fire command station.

The era of atrium buildings in Hong Kong has just begun and many are still under construction and design. They will continue to be a common feature in most of the speculative buildings. Since the fire aspects of atrium buildings are quite different from the other types of buildings, it is necessary to predict the fire environment for designing their fire safety.

\section{Atrium fire simulation}

The fire environment in an atrium fire can be simulated by fire models. Here, a fire is assumed to have occurred in the atrium at floor level and the situation is assumed to be similar to that happening in a large single storey building. But a realistic 'design' fire has to be selected and it should be a growing fire and the fire size and thermal power have to be different for different occupancies. The presence and operation of sprinklers will also affect the growth rate. Because only a few atrium fires have been recorded, no design fire size can be referred to. In this paper, the 'semi-universal' fire growth curve ${ }^{9,18}$ is used. The heat release rate $Q$ is calculated by the following equations and being shown in Fig. 1:

$\mathrm{Q} / \mathrm{Qo}= \begin{cases}\exp (0.025 \mathrm{t}) & \text { for } \\ 40 \exp (0.010(\mathrm{t}-147.6)) & \text { for } 147.6 \mathrm{sec}<\mathrm{t}<147.6 \mathrm{sec} \\ 300 \exp (0.005(\mathrm{t}-349.0)) & \text { for } 349.0 \mathrm{sec}<\mathrm{t}\end{cases}$

Here Qo is the value of Q immediately after ignition and is taken to be $10 \mathrm{~kW}$.

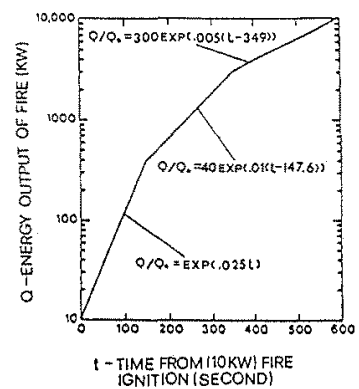

Fig. 1 : Design Fire (From reference no.9) 
The fire environment in an atrium is predicted by the zone model 'FIRST developed at the NIST, USA ${ }^{9}$ and also by the field model developed by Chow ${ }^{6}$. In the zone model simulation, the quantity of smoke generated is estimated by using the point source plume equation ${ }^{19}$. The rate of air entrained $\mathrm{Mp}(\mathrm{z})$ above a fire plume at height $\mathrm{z}$ (and hence the smoke production) is given by:

$$
\mathrm{M}_{\mathrm{p}}(\mathrm{z})=\pi \rho_{\mathrm{a}}(1.2 \alpha \mathrm{z})^{2} \cdot\left[\frac{25 \mathrm{gQ}}{48 \pi \alpha^{2} \mathrm{C}_{\mathrm{a}} \mathrm{T}_{\mathrm{a}} \rho_{\mathrm{a}} \mathrm{z}}\right]^{1 / 3}
$$

where $\quad \alpha=$ entrainment constant

$\mathrm{T}_{\mathrm{a}}=$ ambient air temperature

$\rho_{\mathrm{a}}=$ ambient air density

$\mathrm{C}_{\mathrm{a}}=$ specific heat of ambient air

$\mathrm{Q}=$ energy release rate of the fire

$\mathrm{g}=$ gravitational acceleration

$\mathrm{z}=$ height of smoke layer above fire

Three atria with dimensions shown in Table 1 and Figures 2 and 3 are considered.

\begin{tabular}{|lcc|}
\hline Atrium & Dimension $(\mathrm{L} \times \mathrm{W} \times \mathrm{H})$ & Ground Floor Opening \\
\hline No. 1 & $20 \times 20 \times 50 \mathrm{~m}$ & $5 \times 3 \mathrm{~m}$ \\
No. 2 & $40 \times 20 \times 20 \mathrm{~m}$ & $5 \times 3 \mathrm{~m}$ \\
No. 3 & $20 \times 20 \times 20 \mathrm{~m}$ & $5 \times 3 \mathrm{~m}$ \\
\hline
\end{tabular}

Table $1:$ Dimensions of the Atria

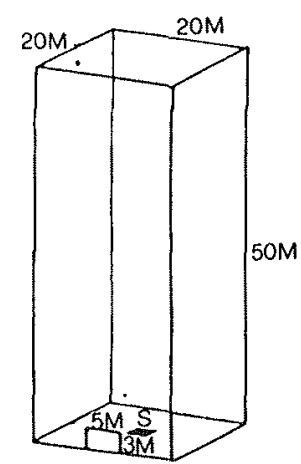

ATRIUM NO.1

$S=3 M \times 3 M$ FIRE SOURCE

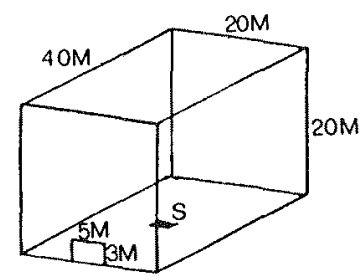

ATRIUMNO.2

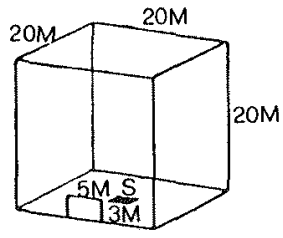

ATRIUM NO. 3

Fig. 2 : Atria Configurations for Zone Model Simulation 

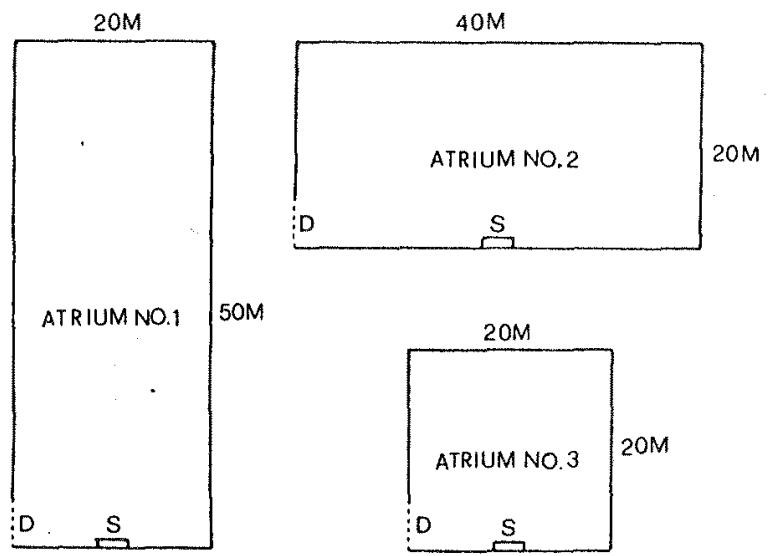

$S=3 M \times 1 M$ FIRE SOURCE

$D=3 \mathrm{M} H I G H$ DOOR OPENING

Fig. 3 : Atria Configurations for Two Dimensional Field Model Simulation

Beside using the 'zone' model, a 'field' model ${ }^{6}$ developed in the Department of Building Services Engineering, Hong Kong Polytechnic is also used. This can simulate the fire-induced field of flow, temperature and smoke concentrations within enclosures. The results obtained can provide guidelines for designing appropriate fire services systems. At present, it is good enough for studying the fire-induced air flow and temperature field at the preflashover stage. The fire plume is fitted by an experimentally determined thermal distribution function which ignores the combustion processes and downward thermal radiation. Those effects are unimportant during the growth stage of a fire. But the results are useful in designing fire systems, since controlling the fire at the early stage is the primary objective in designing, effective fire control systems. Thus, the model provides a means of analyzing a natural convection problem.

The physical picture can be simulated by a system of partial differential equations describing conservation of heat and mass. The general form for an averaged variable $\phi$ is :

$\frac{\partial}{\partial t}(\rho \phi)+\operatorname{div}\left(\rho \vec{v} \phi-\Gamma_{\phi} \operatorname{grad} \phi\right)=S_{\phi}$

Here $\rho$ is the density of air, $S_{\phi}$ being the source term of $\phi$, and $\vec{v}$ is the velocity vector which can be expressed in terms of its components $u, v$ in two-dimensional Cartesian coordinate system. The turbulent effect is described by the $k-\varepsilon$ model. $\phi$ can be the mean values of $u$ and $v$, enthalpy $h$ or turbulence parameters $k$, and $\varepsilon ; \Gamma_{\phi}$ is the effective diffusivity for $\phi$. This system of five partial differential equations for $u, v, h, k$ and $\varepsilon$ is then solved numerically.

The control volume method ${ }^{20}$ is used to discretize the partial differential equations into finite difference forms. The set of 'linear' equations is solved by the SIMPLER (Semi-Implicit Method of Pressure-Linked Equation Revised) algorithm due to Patankar ${ }^{20}$. Further, underrelaxation technique is used for ensuring stability. The solid boundaries are computed from the wall function concerned. 
In the field model simulation, a fire of length $3 \mathrm{~m}$ with heat release rate described by equation (1) is located at the centre of the atrium floor. A two-dimensional simulation is used to save the computer CPU time. The model is described elsewhere ${ }^{6}$ and will not be repeated here. The fire source is uniformly distributed and smoky particles are assumed to be produced at a rate of $5,000 \mathrm{ppm} / \mathrm{s}$. The initial temperature and pressure in the atrium are taken as $300 \mathrm{~K}$ and $101,325 \mathrm{~Pa}$ respectively. Adiabatic conditions are assumed at the wall boundaries and the air in the atrium is stagnant when the fire starts. The boundary conditions for a typical example are shown in Fig. 4.

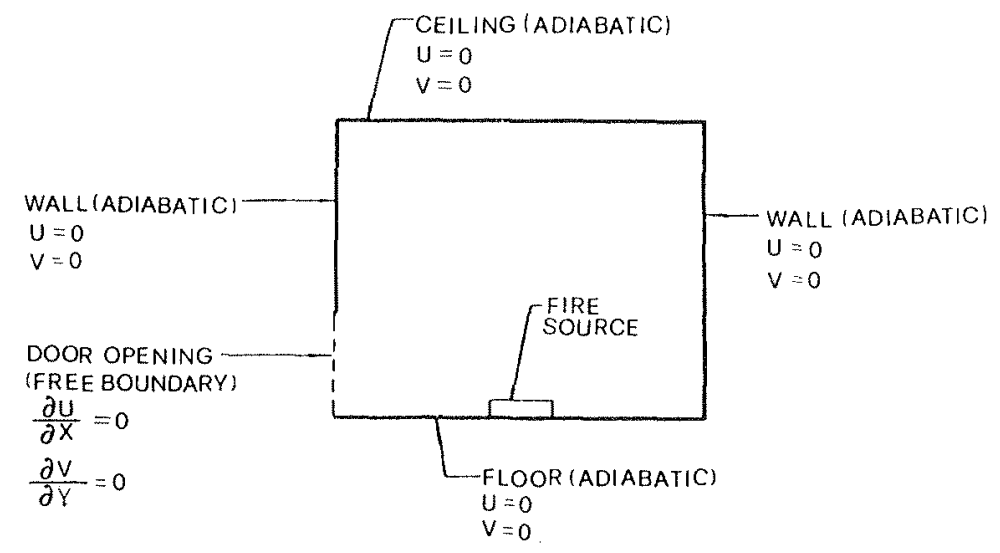

Fig. 4 : Typical Boundary Conditions for Field Model Simulation

\section{(4) Results and discussion}

In the zone model study, the effect of the smoke extraction system on the smoke layer development is also simulated. The smoke extraction system has an extracting rate of 8 air changes per hour and will be actuated 120 seconds after ignition.

Global smoke movement and temperature predictions can be obtained by the zone model while detailed smoke movement and temperature distributions have to be determined by the field model technique. The global smoke development and temperature profile for the three atria predicted by the zone model are plotted in Fig. 5 . The temperature and air flow field predicted by the field model are shown in Figs. 6-8.

From the results given by the zone model, smoke is accumulated in the top of the atrium and will quickly fall to the lower level. At about 5 minutes, the smoke layer will log down to levels of $10 \mathrm{~m}, 10 \mathrm{~m}$ and $5 \mathrm{~m}$ above ground level for atria 1,2, and 3 respectively. At about 8 minutes after the fire has started, the smoke layer will move down to within $2 \mathrm{~m}$ above floor level for all three atria. Under this condition, escape will be difficult. If the atrium is of the open-sided type, compartments above ground level will be affected by smoke. The conditions predicted by the field model are similar with the smoke layer developing very quickly. At 100 seconds, stratified layers are formed at some $15 \mathrm{~m}, 11 \mathrm{~m}$ and $3.5 \mathrm{~m}$ above floor level for atrium no. 1, 2 and 3 respectively. Obviously, the results predicted from the zone model simulation showed that the smoke extraction system is effective and the rate of the growth of the smoke layer is reduced. As much as 8 minutes after ignition, a clear air layer of a height of more than $5 \mathrm{~m}$ is maintained, assisting escape for all the three atria. 

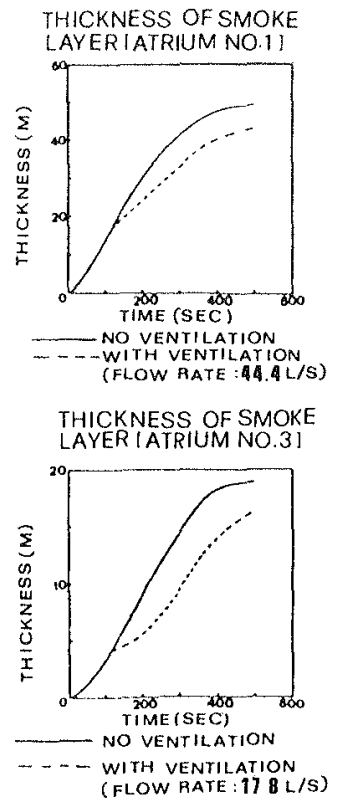

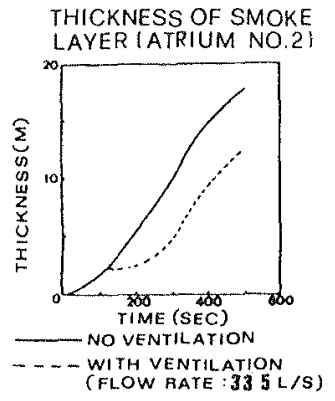

TEMPERATURE PROFILE OF SMOKE IAYER I WITHOUT VENTILATION

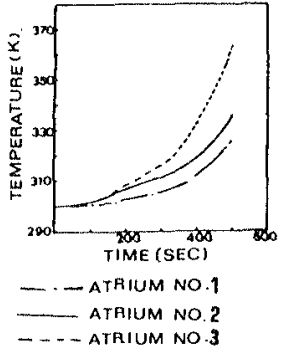

Fig. 5 : Smoke Layer Thickness and Temperature Profile Predicted from Zone Model Simulation

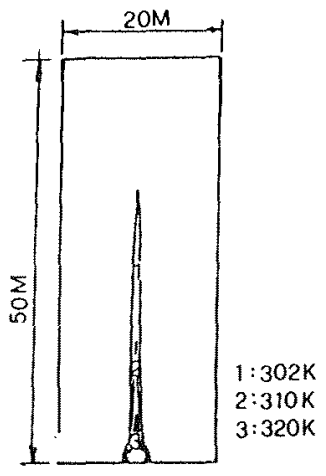

TEMPERATURE CONTOUR

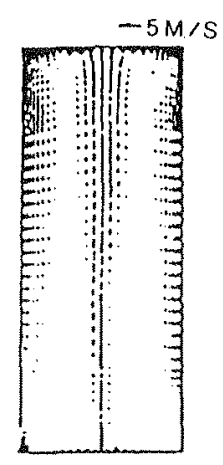

YELOCITY FIELD

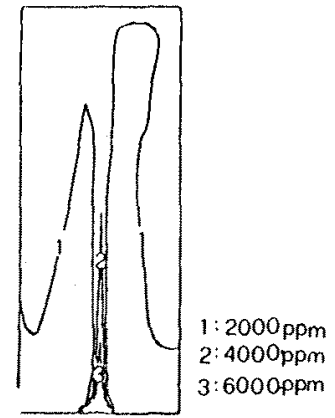

SMOKE CONCENTRATION CONTOUR

Fig. 6: Temperature Contour, Velocity Field and Smoke Concentration Contour for Atium No. 1 Predicted from Field Model Simulation

(At Time $=100 \mathrm{sec}$ ) 


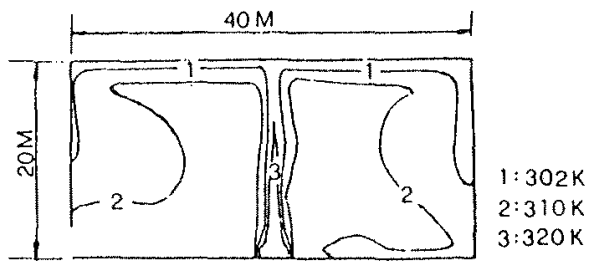

TEAPERATURE CONTOUR

$-1.5 M / S$

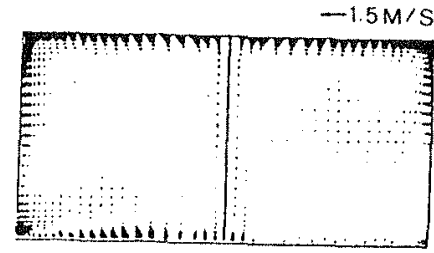

YELOCITY FIELD

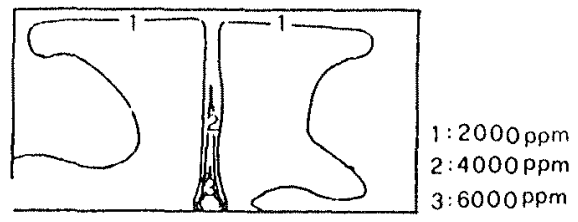

SMOKE CONCENTRATION CONTOUR

Fig. 7 : Temperature Contour, Velocity Field and Smoke Concentration Contour for Atrium No. 2 Predicted from Field Model Simulation (At Time $=100 \mathrm{sec}$ )

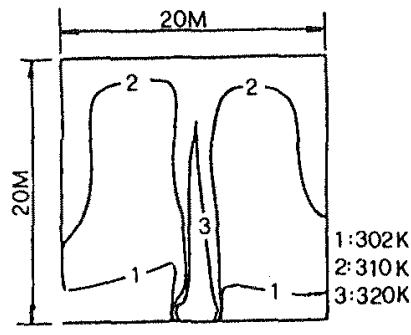

TEMPERATUAE CONTOUR

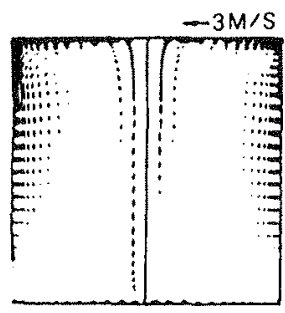

VELOCITY FIELD

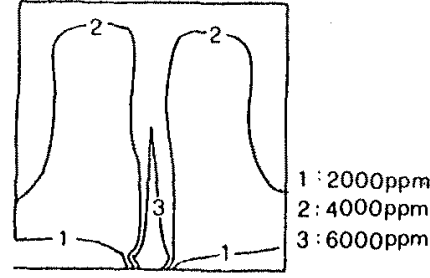

SMOKE CONCENTRATION CONTOUR

Fig. 8 : Temperature Contour, Velocity Field and Smoke Concentration Contour for Atrium No. 3 Predicted from Field Model Simulation

(At Time $=100 \mathrm{sec}$ ) 
The temperature profiles indicated that the temperature of the smoke layer is not very high and would not create a great thermal hazard. The threat caused by temperature rise is therefore less serious than the rapid development of smoke. At 500 seconds after ignition, the fire size is approximately equivalent to $6 \mathrm{MW}$, the temperature of the smoke layer for atria nos. 1,2 and 3 are $325 \mathrm{~K}, 335 \mathrm{~K}$ and $365 \mathrm{~K}$ respectively. If sprinklers are installed in the top of these atria, their actuation time is prolonged and the effectiveness of the such systems is highly questionable.

\section{Conclusions}

Fire scenarios in atria are studied by a zone model FIRST ${ }^{9}$ and a self-developed field model ${ }^{6}$. The temperature profile and smoke layer thickness are predicted. The simulation gives qualitative results and the following points are concluded :

(1) From the numerical results, it is observed that smoke will spread throughout the whole atrium in a very short period which might be less than the designed evacuation time for the occupants. If the atrium is opened to the adjacent compartments, even areas far away from the fire will be influcenced by smoke. This will have psychological and physiological ill effects on the occupants concerned. However this kind of atrium design is commonly found in Hong Kong!

(2) In Hong Kong, only atria with volume larger than $28000 \mathrm{~m}^{3}$ are required to install smoke control systems. From the above predicted results, a smaller atrium will fill with smoke rapidly and the dilution capacity is less. The risk in a small atrium seems therefore not to be lower than that for a large atrium and a smoke control system is deemed to be necessary.

(3) Smoke will give serious problems in an atrium fire. Therefore installing smoke extraction systems is essential in an atrium regardless of its size. If a smoke extraction system is not installed, smoke will accumulate in the top of the atrium first and then descend to a level that may obscure escape routes in a short period.

(4) The temperature profiles show that the smoke layer is not much hotter than ambient for large atrium. In this case, the actuation of the sprinkler heads installed at the top of the atrium is in questionable. Even, if the sprinklers operate, the effect of smoke logging due to the sprinkler water spray will impose additional problems. This is because the hot smoke layer will be cooled by the sprinkler water droplets. As a result, the downward dragging force acting on the smoke layer will be higher than the upward buoyancy. The smoke layer will then become unstable and fall to the lower level ${ }^{21}$.

(5) Finally it should be pointed out that even if smoke extraction system is installed, there are some technical problems. Undersizing of the fan will give an insufficient extraction rate, but oversizing will create a high pressure differential at lower levels and incidentally require a very large emergency generator for supplying power to the extract fan.

(6) Computer fire models, both field and zone, are useful in assessing the fire environment to be encountered. It is difficult to assess which will give the better prediction. Experimental studies must be carried out for validating the models and providing better input parameters.

\section{ACKNOWLEDGEMENT}

This work is supported by the Hong Kong Polytechnic Research Sub-committee and the authors wish to thank Prof. H.S. Ward and Dr. A.M. Marsden for their encouraging supports. 
(1) Saxon R., Atrium Buildings Development and Design, Arch. Press, 1986.

(2) Finnimore B., "The need for atria fire codes", Fire Prevention, 205, 30-33, 1987.

(3) Chow W.K., "Smoke movement and smoke control in atrium buildings", Int. J. Housing Science \& Its Applications, 13, 307-322, 1989.

(4) Sharry J.A., "An atrium fire", Fire Journal, 67: 6, 39-41, 1973.

(5) Lathrop J.K., "Atrium fire proves difficult to ventilate", Fire Journal, 73: 1, 30-31, 1979.

(6) Chow W.K. \& Leung W.M., "Solid wall boundary effect on a building field model", Combustion Science Technology, 71: 1-3, 77-93, 1990.

(7) Markatos N.C., Malin M.R. \& Cox G., "Mathematical modelling of buoyancy induced smoke flow in enclosures", Int. J. of Heat \& Mass Transfer, 25: 1, 63-75, 1982.

(8) Liu V.K. \& Yang K.T., "Undsafe-II: a computer code for buoyant turbulent flow in an enclosure with thermal radiation", NBS-GCR-78-150, U.S. National Institute of Standard and Technology, Gaithersburg, MD, 1978.

(9) Cooper L.Y., "A mathematical model for estimating available safe egress time in fire", Fire and Materials, 6, 135-144, 1982.

(10) Mitler H.E. \& Emmon H.W., "Documentation for the 5th Harvard computer fire code", Division of Eng. and Applied Sci. Report 45, Harvard University, 1981.

(11) Tanaka T., "A model of multiroom fire spread", NBSIR-83-2718, U.S. National Institute of Standard and Technology, Gaitherburg, MD, 1983.

(12) Mitler H.E. \& Rockett J.A., "User's guide to FIRST, a comprehensive single room fire model", NBSIR 87-3595, U.S. National Institute of Standard and Technology, Gaithersburg, MD, 1987.

(13) Ross D.E., Lewis W.S., LoPinto A., Wong S.P.W., Wong A. \& Mak H.C., "Case Study: Bank of China Building", The Journal of Hong Kong Institution of Engineers, May, 1989.

(14) "Hong Kong Bank headquarters building : an eye-catching 'space-scraper' explores the Hong Kong skyline", Building Journal Hong Kong, August, 63-70, 1985.

(15) "New Town Plaza : Texas-size in Shatin", Building Journal Hong Kong, December, $79-82,1984$.

(16) "Code of practice for fire services installation and equipment", Hong Kong Fire Services Department.

(17) Chow W.K., "Sprinkler in atrium buildings", The Hong Kong Engineer, September, 41-43, 1988.

(18) Friedman R., "Quantification of threat from a rapidly growing fire in terms of relative materials properties", Fire \& Materials, 2 27-33, 1978.

(19) Morton B.R., Taylor G.I. \& Turner J.S., "Turbulent gravitational convection from maintained and instantaneous sources" Proc. of Royal Soc. (London), A234, 1-20, 1956.

(20) Patankar S.V., Numerical Heat Transfer and Fluid Flow, McGraw Hill - Washington D.C., 1980.

(21) Chow W.K. \& Fong N.K., "Numercial studies on the interaction between a sprinkler water spray and a natural venting inside a building", Proceed of the Heat \& Mass Transfer in Fire Session, 5th AIAA/ASME Thermo physical \& Heat Transfer Conference, Seattle, Wa U.S.A. p. 93-100, 1990. 